40 (3) | 2011

Varia

Lima, 10-13 de agosto de 2011

\title{
Simposio Internacional: «Historia de la Arqueología en el Perú del siglo XX»
}

Lima, 10-13 de agosto de 2011

\section{Henry Tantaleán}

\section{(2) OpenEdition}

Journals

Edición electrónica

URL: http://journals.openedition.org/bifea/1366

DOI: 10.4000/bifea.1366

ISSN: 2076-5827

\section{Editor}

Institut Français d'Études Andines

\section{Edición impresa}

Fecha de publicación: 1 diciembre 2011

Paginación: 615-619

ISSN: 0303-7495

\section{Referencia electrónica}

Henry Tantaleán, «Simposio Internacional: «Historia de la Arqueología en el Perú del siglo XX» »,

Bulletin de l'Institut français d'études andines [En línea], 40 (3) | 2011, Publicado el 01 junio 2012, consultado el 07 noviembre 2020. URL : http://journals.openedition.org/bifea/1366 ; DOI : https:// doi.org/10.4000/bifea.1366

Les contenus du Bulletin de l'Institut français d'études andines sont mis à disposition selon les termes de la licence Creative Commons Attribution - Pas d'Utilisation Commerciale - Pas de Modification 4.0 International. 


\section{Eventos}

\section{SIMPOSIO INTERNACIONAL: «HISTORIA DE LA ARQUEOLOGÍA EN EL PERÚ DEL SIGLO XX»}

\section{Lima, 10-13 de agosto de 2011}

Durante los días 10, 11, 12 y 13 de agosto de 2011 se celebró en la ciudad de Lima el Simposio Internacional «Historia de la Arqueología en el Perú del siglo XX». Dicho evento fue organizado por el Instituto Francés de Estudios Andinos (UMIFRE 17, CNRS-MAEE) y estuvo coordinado por los arqueólogos Henry Tantaleán y César Astuhuamán. Adicionalmente, el evento fue auspiciado por el Centro Cultural de la UNMSM, el Cotsen Institute of Archaeology de la Universidad de California en Los Ángeles, el Institute of Andean Research, la Municipalidad Distrital de Miraflores, la Unidad Ejecutora 003 Zona Arqueológica de Caral, la empresa de arqueología Asesoría y Servicios Especializados S. A. (ASE) y la Embajada de la República de Polonia en el Perú.

Durante esos intensos 4 días se dieron reunión tanto arqueólogos nacionales como de diferentes países (Estados Unidos de América, Alemania, Italia, Francia, Polonia, Japón, España y Argentina) para hablar sobre el desarrollo de la Arqueología en el Perú durante el siglo XX. En total, se ofrecieron 24 ponencias de especialistas en el tema que los coordinadores invitamos para este efecto dada su trayectoria, estudio del tema y publicaciones relacionadas con la historia de la Arqueología o su relación con instituciones o proyectos extranjeros en el Perú, lo cual, como esperábamos, generó una visión bastante amplia y crítica de la historia de la arqueología en el contexto del Estado peruano. Asimismo, se tuvo un promedio de 120 asistentes durante cada sesión del simposio, los cuales fueron inscritos previamente bajo un sistema de selección que priorizaba su interés objetivo en la reunión.

El propósito principal de la reunión fue la de reunir a la mayor cantidad de especialistas de diferentes nacionalidades y posiciones teóricas y metodológicas para conocer la forma tan especial en la que se ha construido la Arqueología en el Perú. Justamente, la imagen que se eligió para esta reunión, cedida gentilmente 


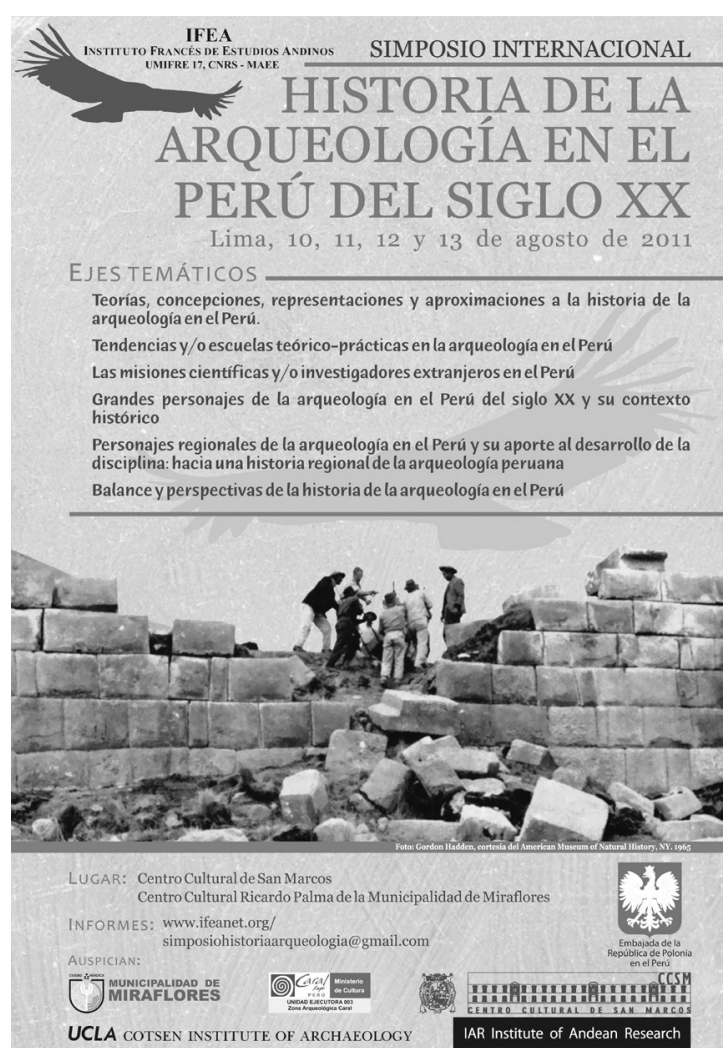

por el American Museum of Natural History de Nueva York, fue la del momento de la reconstrucción del ushnu o plataforma principal de la ciudad Inca de Huanucopampa en la década de 1950, liderada por John Victor Murra, la cual metafóricamente hablaba de esa imagen de la construcción de la Arqueología en el Perú, bloque a bloque, por parte de investigadores de diferentes procedencias y perspectivas. De esta manera, por primera vez, aunque con algún antecedente previo en una reunión que hablaba especialmente de la Arqueología en el Perú durante el siglo XIX, nos reunimos en esta ocasión para historizar de manera orgánica y sistemática a la arqueología peruana.

Los coordinadores de este evento entendieron que el estudio del desarrollo histórico de la práctica y del pensamiento arqueológico ha sido motivo de debates nacionales e internacionales, publicaciones e intereses tanto dentro de la academia como fuera de ella. Sin embargo, la tradición clásica de hacer historia de la Arqueología se distanció «respetuosamente» de sus personajes clave y terminó en muchos casos mitificando su figura, convirtiéndolos en agentes sobresalientes en la construcción de genealogías de la historia de la arqueología peruana. De esta manera, casi siempre se había terminado narrando y reproduciendo una historia oficial en la que los grandes pioneros de la Arqueología habían transformado o revolucionado el pensamiento arqueológico, y ensombreciendo con su figura a otros individuos o colectivos que terminan siendo invisibilizados en esas grandes historias de la Arqueología en el Perú.

Los coordinadores fueron conscientes de que esta perspectiva tradicional estaba presente en la academia nacional, pero también observamos que una nueva generación de arqueólogos y arqueólogas había comenzado a reflexionar acerca de este proceder y había profundizado en las causas que generaron la existencia de ciertos fenómenos sociales en los cuales se encontraban involucrados los arqueólogos e investigadores del pasado prehispánico. Este estudio más detenido también hizo patente que muchos de los planteamientos de los investigadores más prominentes del siglo XX ya habían sido puestos en práctica en otros lugares del mundo con diferentes consecuencias. 
Por todo lo anteriormente reflexionado, los coordinadores del evento, han pensado revisitar la historia de la Arqueología por diversas razones que ya han sido planteadas en la última década (v. g. colonialismo académico, relación entre política y Arqueología, etc.), a partir de aproximaciones y métodos novedosos, como el estudio de la correspondencia y documentos administrativos, documentación que antes no había sido tomada en cuenta y que ha permitido conocer otras dimensiones de quiénes investigan el pasado.

Sin embargo, la anterior perspectiva no pretendió ser desplazada en el simposio sino que, más bien, se articuló y confrontó con otra en la que se hizo evidente que otros actores y actrices contribuyeron a formar esa amalgama de teorías y prácticas llamada Arqueología en el Perú. De esta manera, se pudo vislumbrar un paisaje más diverso y menos esquemático, lo cual definitivamente devendrá en nuevas líneas de investigación sobre la historia de la disciplina arqueológica.

En ese sentido, este simposio convocó a investigadores e investigadoras que ayudaron a comprender ese frondoso bosque Ilamado Arqueología en el Perú a través de su historia, situando a los diferentes actores y actrices dentro del contexto histórico al que pertenecieron y ayudaron a reproducir sin abandonar la perspectiva y percepción de ellos dentro de la disciplina. De esa manera, se pudo contar con una perspectiva externalista e internalista de la historia de la Arqueología en el Perú durante el siglo XX, lo cual, sin duda, ayudará a entender la práctica arqueológica de nuestros días.

Para organizar las ponencias por temas con el fin de analizar la historia de la Arqueología en el Perú del siglo XX, se establecieron los siguientes ejes temáticos:

- Teorías, concepciones, representaciones y aproximaciones a la historia de la Arqueología en el Perú.

- Tendencias y/o escuelas teórico-prácticas en la Arqueología en el Perú.

- Las misiones científicas y/o investigadores extranjeros en el Perú.

- Grandes personajes de la Arqueología en el Perú del siglo XX y su contexto histórico.

- Personajes regionales de la Arqueología en el Perú y su aporte al desarrollo de la disciplina: hacia una historia regional de la Arqueología peruana.

- Balance y perspectivas de la historia de la Arqueología en el Perú.

Así, el día miércoles 10 de agosto en la Capilla de la Virgen de Loreto del Centro Cultural de la UNMSM se dio la ceremonia y charla inaugural ofrecida por el Dr. Richard Daggett. Además, se contó con la presentación de dos libros auspiciados gracias a fondos de la embajada de Francia: Moche: Pasado y Presente de Santiago Uceda y Ricardo Morales y Huaca de las Balsas Tucume: Arte Mural de Lambayeque de Alfredo Narváez y Bernarda Delgado. Este evento contó con la presencia de autores y comentaristas y fue presidida por la, entonces, embajadora de Francia en el Perú Cécile Pozzo di Borgo. Asimismo se contó con las palabras del director del IFEA, Georges Lomné y de los coordinadores del evento como parte de este acto de apertura del simposio. 
Al día siguiente, jueves 11 de agosto, las mesas — organizadas por ejes temáticos— comenzaron en el Salón General del Centro Cultural de la Universidad Nacional Mayor de San Marcos. Ese primer día se dieron dos mesas. La primera, denominada «Teorías, concepciones, representaciones y aproximaciones a la historia de la Arqueología en el Perú», tenía como objetivo principal ofrecer un panorama de los principales momentos, temas, conceptos e ideas que se dieron por parte de los investigadores y arqueólogos en el siglo XX en el Perú. En esta mesa expusieron sus temas los investigadores Richard Daggett, Ann Peters y Alberto Ayarza, Monica Barnes, Henry Tantaleán y Luis Jaime Castillo. Al final de la mesa, Gabriel Ramón realizó importantes comentarios a las ponencias expuestas.

La siguiente mesa, Ilamada «Tendencias y/o escuelas teórico-prácticas en la Arqueología en el Perú», tenía como objetivo presentar las principales teorías y metodologías arqueológicas que se habían desarrollado en el Perú. Si bien este es un mundo lleno de diversos planteamientos, quisimos abordar las teorías que, a nuestro parecer, habían sido características o las más populares en el Perú y practicadas por arqueólogos nacionales y extranjeros. Así tuvimos las ponencias de Jorge Silva, John Rick, Ruth Shady, Rafael Vega-Centeno y Gustavo Politis. La mesa se cerró con los comentarios a las ponencias por parte de Henry Tantaleán.

Los días viernes 12 y sábado 13 de agosto, el simposio se trasladó al auditorio principal del Centro Cultural «Ricardo Palma» de la Municipalidad de Miraflores. Las sesiones del día viernes se enfocaron en los aportes, influencias y contribuciones de los investigadores extranjeros a la arqueología del Perú y fue denominada «Las misiones científicas y/o investigaciones extranjeras en el Perú del siglo XX». La primera conferencia, y como un homenaje a su trayectoria, estuvo a cargo de la Dra. Danièle Lavallée. Posteriormente ofrecieron sus ponencias Elmo León, Kzrysztof Makowski y Yuji Seki. Los comentarios estuvieron a cargo de Denise Pozzi-Escot. Por la tarde y, siguiendo esta temática, tuvimos las importantes ponencias de Giussepe Orefici (leída por el codirector del Proyecto Nasca: Ángel Sánchez), Pedro Castro-Martínez, Colin McEwan, Bill Sillar y Charles Stanish. Para esta parte de la mesa, los comentarios estuvieron a cargo de Carlos del Águila.

El día sábado 13 de agosto por la mañana, en la mesa denominada «Personajes regionales de la Arqueología en el Perú y su aporte al desarrollo de la disciplina: hacia una historia regional de la arqueología peruana», se quiso vislumbrar las contribuciones de otros investigadores menos referidos en la historia de la Arqueología en el Perú. Asimismo, el objetivo era ver, aunque sea de manera sintética, cómo se había estado dando la arqueología paralelamente a la que se hacía en la capital del Estado peruano. Aquí tuvimos las contribuciones de Gabriel Prieto, Santiago Uceda y Pedro Novoa. Los comentarios estuvieron a cargo de César Astuhuamán.

La tarde fue dedicada a las grandes luminarias de la Arqueología en el Perú en la mesa titulada «Grandes personajes de la arqueología en el Perú del siglo XX y su contexto histórico». En esta mesa tuvimos la fortuna de contar con Peter Kaulicke, 


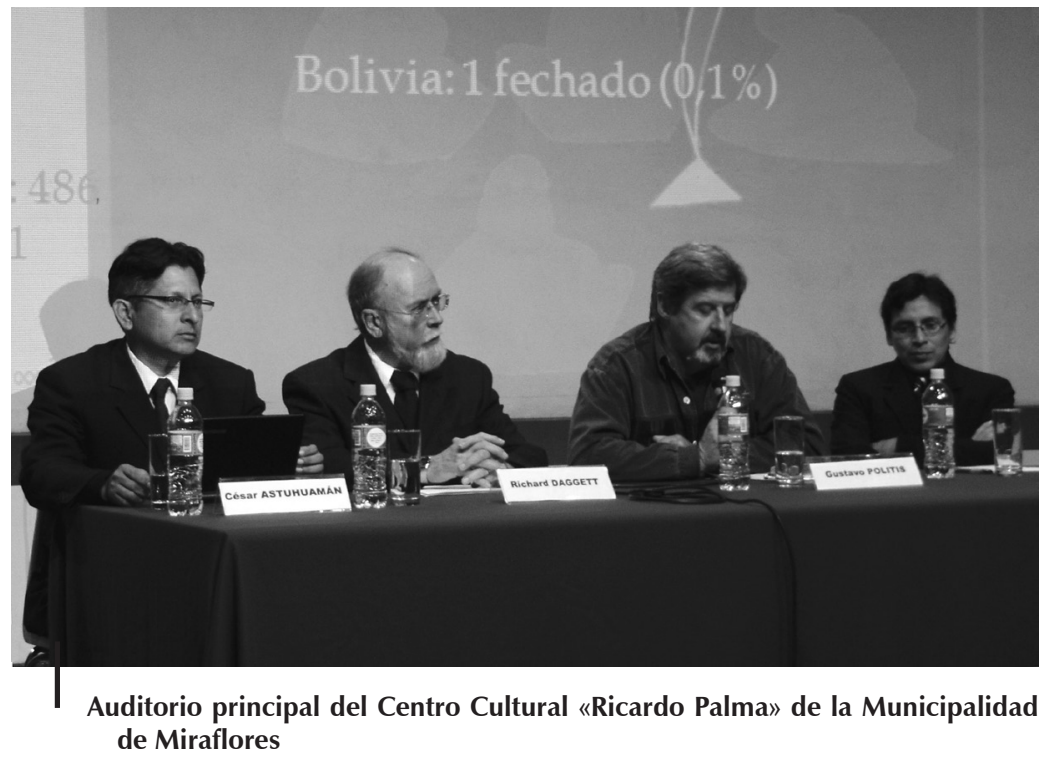

De izquierda a derecha: César Astuhuamán, Richard Daggett, Gustavo Politis y Henry Tantaleán

César Astuhuamán, Segundo Vásquez y Gabriel Ramón. Finalmente, el simposio se cerró al terminar la tarde con los comentarios y balances realizados por Richard Daggett, Gustavo Politis y los coordinadores.

Finalmente queremos agradecer a los auspiciadores y a todos los que han colaborado en la organización del evento, en particular el personal del IFEA y los estudiantes de la UNMSM. Permitieron que todas las actividades planificadas y el mismo desarrollo del evento fuesen realizados con éxito.

Creemos que este evento ha generado un nuevo interés por el estudio sistemático de la historia de la arqueología del Perú. Esta primera discusión formal y la síntesis en la que colaboraron diferentes autores tanto nacionales como extranjeros de diferentes generaciones será publicada próximamente. 